\title{
POLICIES AND FINANCING TO SPUR APPROPRIATE PRIVATE-SECTOR ENGAGEMENT IN FOOD SYSTEMS
}

\section{IMPLICATIONS FOR MAINSTREAMING AGROBIODIVERSITY}

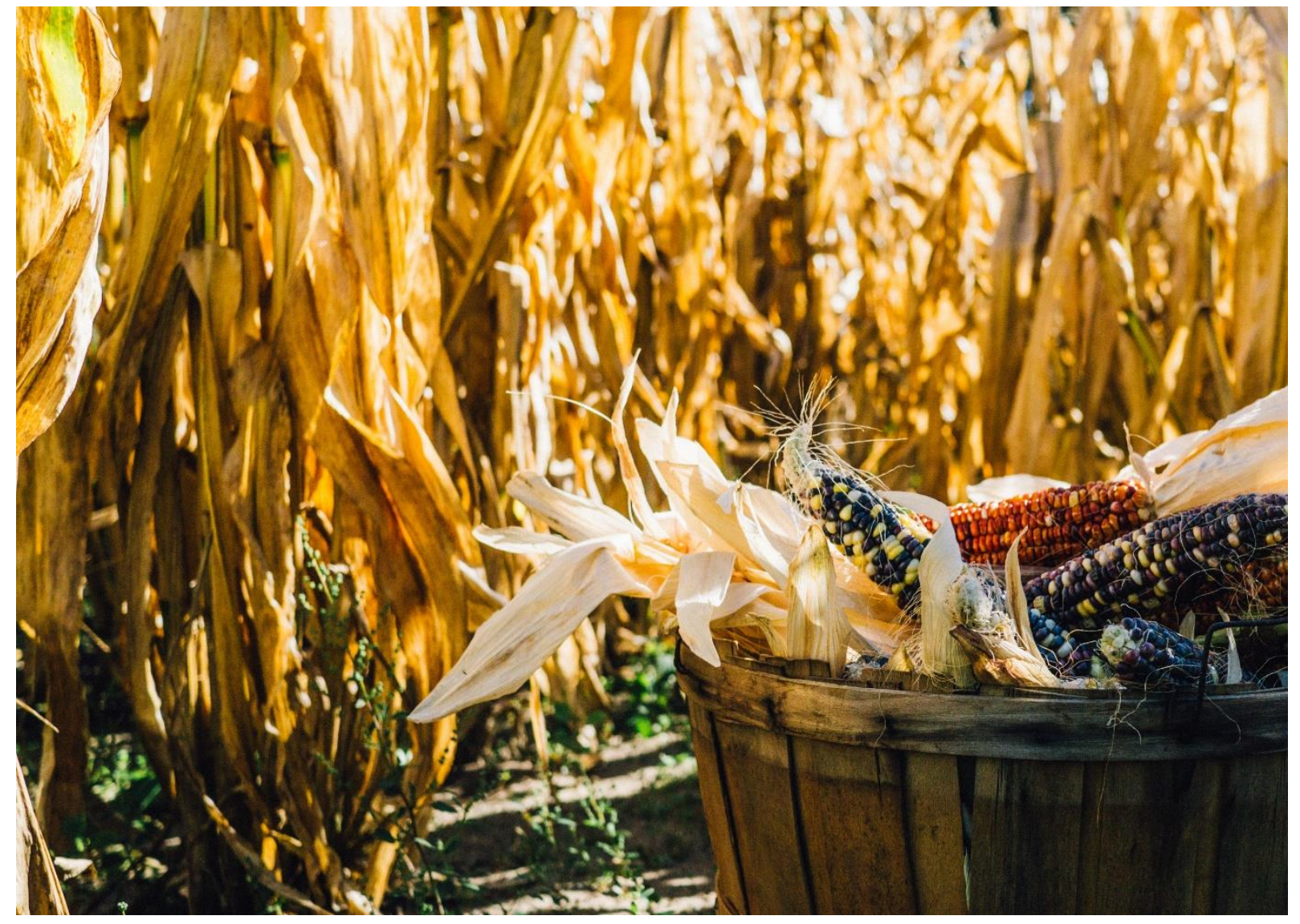

\section{GAIN Discussion Paper Series $n^{\circ} 2$}

November 2019

Greg S. Garrett, Laura Platenkamp, Mduduzi N.N. Mbuya

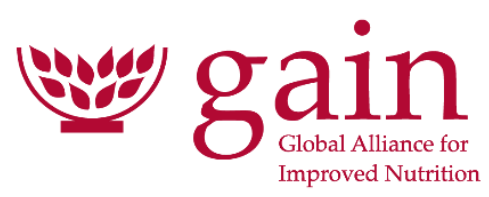




\section{ABOUT GAIN}

The Global Alliance for Improved Nutrition (GAIN) is a Swiss-based foundation launched the UN in 2002 to tackle the human suffering caused by malnutrition. Working with governments, businesses and civil society, we aim to transform food systems so that they deliver more nutritious food for all people, especially the most vulnerable.

\section{Recommended citation}

Garrett, G.S., Platenkamp, L., Mbuya, M.N.N Policies and Finance to Spur Appropriate Private Sector Engagement in Food Systems. Global Alliance for Improved Nutrition (GAIN). Discussion Paper 2. Geneva, Switzerland, year. DOI: https://doi.org/10.36072/dp.2

\section{(C) The Global Alliance for Improved Nutrition (GAIN)}

This work is available under the Creative Commons Attribution-Non-Commercial-Share Alike 4.0 IGO licence (CC BY-NC-SA 4.0 IGO; https://creativecommons.org/licenses/by-nc-sa/4.0/). Under the terms of this licence, you may copy, redistribute and adapt the work for non-commercial purposes, provided the work is appropriately cited, as indicated below. In any use of this work, there should be no suggestion that GAIN endorses any specific organisation, products or services. The use of the GAIN logo is not permitted. If you adapt the work, then you must license your work under the same or equivalent Creative Commons license. The contributions of third parties do not necessarily represent the view or opinion of GAIN.

\section{Acknowledgements}

We would like to thank various GAIN donors, notably the Government of the Netherlands and the Bill and Melinda Gates Foundation, for their ongoing support of GAIN's private-sector engagement, which has informed a number of the themes in this paper. Also, we thank Arwen Bailey, Knowledge Management and Science Communication Specialist at Bioversity International and Stella Nordhagen at GAIN for their helpful edits and feedback during the writing of this paper and other anonymous reviewers for their helpful suggestions.

All photographs included in this document have been taken with consent for use in publications.

\section{GAIN DISCUSSION PAPER SERIES}

The GAIN Discussion Paper series is designed to spark discussion and debate and to inform action on topics of relevance to improving the consumption of nutritious, safe foods for all, especially the most vulnerable.

The Global Alliance for Improved Nutrition (GAIN)

Rue de Varembé 7

1002 Geneva

Switzerland

T: +41 227491850

E: info@gainhealth.org

www.gainhealth.org 


\section{SUMMARY}

There is increasing evidence that improved agrobiodiversity (that is, the diversity of crop and livestock genetic resources - domesticated or wild - which contributes to agriculture and food production) can enhance human nutrition through several pathways. These include the provision of genetic resources for future adaptation (e.g., biofortification), improving dietary diversity and quality, and enhancing income. However, shifting food systems towards the provision of more biodiverse, sustainable, and healthy diets will take time.

There are public policies as well as private financing approaches that have potential to stimulate the production and consumption of more agrobiodiverse food. These include fiscal policies and subsidies as well as innovative financing initiatives, which aim to increase the production of affordable, nutritious foods. In addition, there are a few examples of large private sector-led initiatives that are helping to drive change.

This paper summarises a number of these policies, financing mechanisms, and private-sector initiatives and discusses how each approach might be applied in order to mainstream agrobiodiversity within food systems to reduce the risk of poor nutrition and improve planetary health.

- Industry players - from smallholder farmers to multinational companies - are critical actors in the food system and have a collective role to play in shaping and conserving agrobiodiversity.

- The private sector requires more incentives and meaningful deterrents to shift food systems towards the provision of more biodiverse, sustainable, and healthy diets.

- There are public policies as well as private financing mechanisms that appear to be improving appropriate private-sector production and productivity techniques and outputs. These include fiscal policies and subsidies as well as blended financing initiatives.

- In addition, a handful of large private sector-led initiatives are helping to drive change. 


\section{BACKGROUND AND OBJECTIVE}

Agrobiodiversity can be defined as the variety and variability of crops and livestock domesticated or wild - which contribute to agriculture and food production as either inputs or outputs (1). It can increase resilience of farm production to climate change, enhance soil health, and water quality while reducing the need for costly artificial inputs, such as fertilisers and pesticides, in food production systems (1). Farming systems that are high in agrobiodiversity produce lower greenhouse gas emissions than those with less agrobiodiversity (2). For these reasons, agrobiodiversity can help reduce risks to planetary health from agriculture.

The linkage between agrobiodiversity and human health is more difficult to estimate due to the complexity and dynamism of the food system. There are suggestions that improved agrobiodiversity can be linked to improvements in diets and nutrition (3), but empirical studies suggest a more modest linkage between production diversity and consumption diversity that is dependent on functioning markets $(4,5)$. Though further research is needed, the notion that agrobiodiversity can have long-term benefits for food security and nutrition remains plausible and largely uncontested. Agrobiodiversity can plausibly contribute to human nutrition through several pathways including the provision of genetic resources for future adaptation (e.g. biofortification), improving dietary diversity and quality, and enhancing income (6). The 2019 EAT-Lancet Commission Report underscores this by emphasising the inextricable links between human health and planetary health, considering environmental constraints, healthy diets, and population growth trends (7).

Industry players - from smallholder farmers through to multinational companies - are critical actors in the food system. Because they facilitate the maintenance of environmental and genetic resources and the adoption of supportive agricultural management systems and practices, they have a collective role to play in shaping and conserving agrobiodiversity. Shifting food systems towards the provision of more biodiverse, sustainable, and healthy diets will take time. More appropriate and effective private-sector engagement and action is critical towards this outcome. Here we argue that the private sector requires more incentives to use agrobiodiversity and to produce and market the components of healthy diets. It also needs meaningful deterrents to reduce the production and marketing of unhealthy components, such as sugar-sweetened beverages.

Fortuitously, there are public policies and private financing mechanisms that appear to be improving private-sector production and productivity. These include fiscal policies and subsidies as well as innovative financing initiatives that are increasing the production of affordable, nutritious foods (8). In addition, a handful of large private sector-led initiatives are helping to drive change.

This paper summarises an illustrative selection of these policies, financing mechanisms, and private-sector initiatives that relate to the provision of nutritious foods in different contexts and discusses how each approach might be applicable for mainstreaming agrobiodiversity in food systems to reduce the risks of poor nutrition and improve planetary health. 


\section{DIET-RELATED PUBLIC POLICIES}

\subsection{FISCAL POLICIES AND SUBSIDIES}

Fiscal policies in food systems can be traced back at least a century, to when Finland started taxing sugary foods in 1926 (9). Since 2011, when the UN General Assembly recommended 'fiscal measures' as one approach to improve diets, momentum has been growing to use these instruments in national health and nutrition plans (10). Taxation and subsidies can increase the purchase of healthier foods and decrease the purchase of products high in salt, fat, or sugar. A 2016 systematic review on the effectiveness of these policies indicated that taxing sugar-sweetened beverages generally increased the price, leading to a subsequent decrease in demand (11). Further, the review found that taxation and subsidies can lead to an increase in the purchase of healthier foods and a decrease in the purchase of products high in salt, fat, or sugar (11).

Today, 39 countries report using fiscal policies to drive improved dietary intake, with more than half of these countries increasing taxes on unhealthy foods and beverages (Figure 1). These policies generally result in a reduction in net energy intake, which could prevent further growth in obesity prevalence in the countries where they are implemented (10). Of the reporting countries, $23 \%$ use fiscal policies to improve dietary intake by subsidising common items like cereals, yoghurt, cheeses, milk, oils, fresh meat, fruits, and vegetables (10).

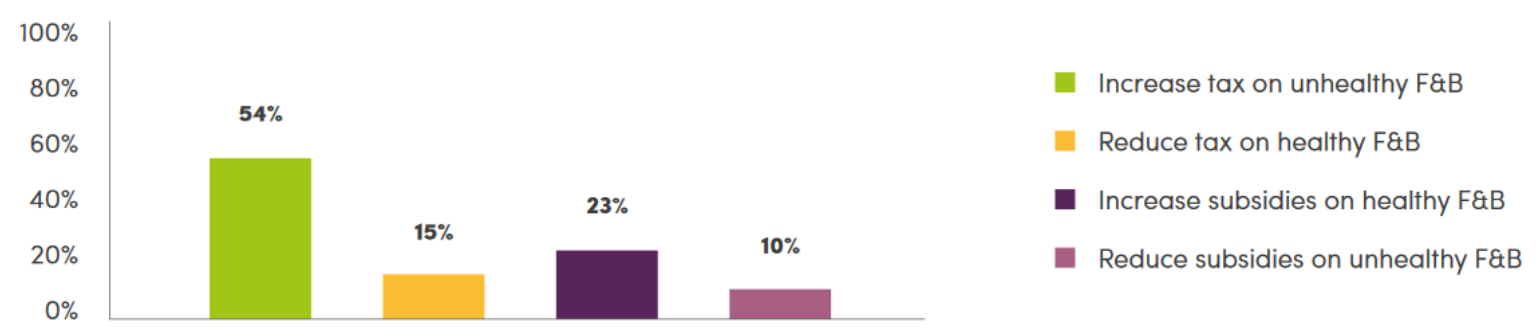

Figure 1: Type of fiscal policies influencing foods and beverages (F\&B) among 39 countries reporting. Replicated with permission from (10).

\section{HOW COULD FISCAL POLICIES AND SUBSIDIES BE USED TO SUPPORT THE UPTAKE OF BIODIVERSE FOODS FOR HEALTHY DIVERSE DIETS?}

The evidence suggests that well-designed food-related fiscal policies and subsidies can improve diets, preventing growth in overweight and obesity, which in turn are linked to the development of non-communicable diseases (12). Reducing tax and increasing subsidies on nutrient-dense foods, for instance fruits, vegetables, and high-nutrient local cereals (e.g. millets, sorghum, quinoa) could be an effective way to nudge consumer behaviour towards healthier diet choices. By similar logic, they could also stimulate the production and consumption of more agrobiodiverse food. Therefore, it is worth examining the potential fiscal policies that are beneficial to public health as well as to agrobiodiversity. In theory, a well-designed, coherent sugar-related tax, for example, could disincentivise the amount and type of sugar produced, leading to lower cultivation of sugar crops. This would in turn free space for increased production of other species, reversing the loss of agrobiodiversity associated with sugarcane monocropping (13). Similarly, well-designed edible oil taxes could 
help mitigate monocropping of palm oil. Palm oil is linked to an increase in cardiovascular disease, and its production, which has increased greatly over the last decades, has contributed to $8 \%$ of global deforestation, mainly in Indonesia and Malaysia (13). Furthermore, the revenues generated from these food taxes could be reinvested to encourage more biodiverse food systems. Examples of such reinvestment of tax revenue include the Healthy Diné Nation Act by the Navajo Nation, which uses revenues generated by taxing unhealthy food products to fund projects in farming, greenhouses, vegetable gardens, and farmers' markets, and French Polynesia, where revenue from taxes on sweetened drinks, confectionery, and ice cream was earmarked for health (14).

\subsection{MICRONUTRIENT-SPECIFIC POLICIES}

Biofortification and large-scale industrial food fortification have become important interventions to improve nutrition through public-private collaboration in many low- and middle-income countries (LMICs) (17). Public-private partnerships are critical to ensure each intervention reaches its desired public health impact by taking advantage of the government's respective strengths in regulation and public oversight as well as the deep market penetration and innovations in processing, marketing, and communication of the private sector (18).

Large-scale food fortification is one of the best examples in the food and nutrition sector of a scaled and impactful systemic partnership between business and government (15). Food fortification policies typically require an entire nation's staple food processing industry to add specific levels of micronutrients to the target foods. Today, 88 countries mandate the fortification of at least one kind of cereal grain (Figure 2) (16). Tens of thousands of small, medium, and large food processing companies add nutrients to foods, resulting in significant health impacts and ongoing prevention of micronutrient deficiencies (17).

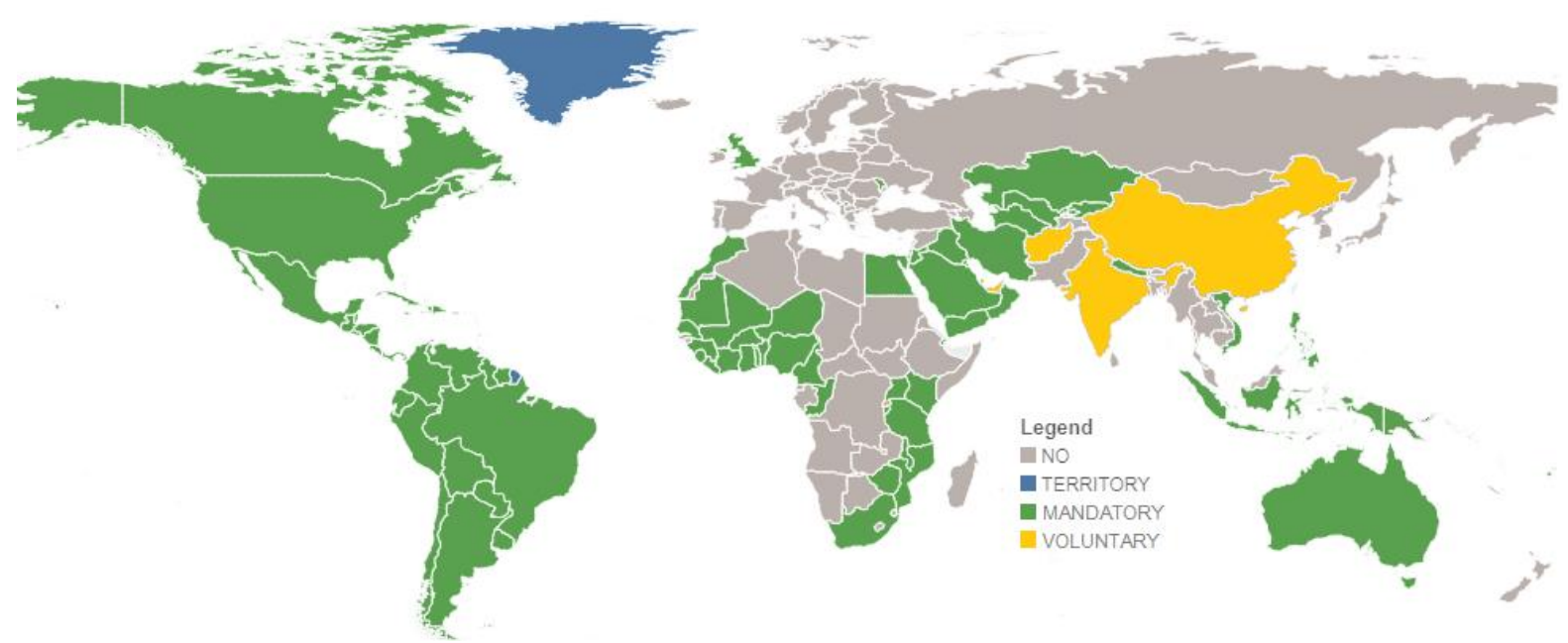

Figure 2 - Legislation for the fortification of grains (wheat, maize, or rice). Source: [16]; permission for reproduction not required.

Biofortification, or breeding crops to increase their nutrient content, complements both dietary diversity and industrial food fortification. It is now supported by approximately 30 governments and delivers vitamins and minerals to more than 20 million people in farm households who have limited access to micronutrients (18). Most of these governments have formally integrated biofortification into their nutrition and agriculture policies (18). 
In order to better support agrobiodiversity, micronutrient deficiency mitigation policies, which encourage biofortification and large-scale food fortification of staple crops, should start to look at complementing these with policies that encourage increased production and consumption of naturally occurring, nutrient-dense species and varieties. This is particularly relevant in agroecological contexts where traditional varieties may be more appropriate or economical than modern varieties due to lower agricultural input and water resource needs. Governments can build on these policies to promote and encourage smallholder farmers to grow existing but less-known crop species and varieties that are high in micronutrients. Examples of neglected crops that have been selected for stressful conditions, can be cultivated using low-input techniques, and can offer an alternative source of micronutrients (19) include arrowroot, cassava, and cowpea in Mozambique; all are good sources of provitamin A (20). Overall, one advantage of this approach could be an increase in the use of traditional crops, that may be more culturally relevant and adapted to local ecologies.

In addition, policymakers could focus on agrobiodiversity policies that reinforce dietary diversity and better situate biofortification within the larger context of sustainable food-based approaches. Last, policies targeting the food processing industry to add micronutrients to staple crops at the processing stage can ensure that micronutrient awareness campaigns for the general population are well designed and effectively targeted. An explicit focus should be to improve consumers' knowledge, acceptance, and uptake of both traditional and modern sources of micronutrients in the diet with a recognition of dietary diversity as the aspirational ideal.

\section{PRIVATE FINANCING FOR MORE SUSTAINABLE, NUTRITIOUS FOOD SYSTEMS}

There are significant opportunities for investing responsibly in the agri-food industry, and this financing is key in driving change towards more a more sustainable, food-secure future (21). According to the Business and Sustainable Development Commission, business opportunities related to achieving the food-related Sustainable Development Goals could be worth more than US\$2 trillion a year by 2030 (20). LMICs represent more than two-thirds of this opportunity (22). This includes up to US $\$ 255$ billion in meeting the increasing food requirements of people emerging out of extreme poverty, up to US $\$ 405$ billion in reducing food waste in value chains, and up to US $\$ 200$ billion in the reformulation of products in order to increase nutritional value.

For example, there are currently over one billion people in the African consumer market, and expectations are that this is going to increase to over 2 billion by 2050 (23). Over 220 million of these current consumers are between ages 15 and 25 (24). An estimated 80\% of Africa's food consumption is marketed and handled mostly through private operators, making the private sector crucial for food security.

Most of these are small and medium-sized enterprises (SMEs), which represent $30-40 \%$ of the value added in food value chains (25). Financing the agri-food industry, especially SMEs, 
represents a large opportunity to improve sustainable, nutritious diets if done in a smart and responsible way. However, there are barriers. A study commissioned by GAIN and completed by Dalberg in late 2017 found that for over 300 African SMEs, access to finance was the top barrier to growing the delivery of nutritious foods (26). In May 2018, GAIN commissioned iGravity Impact Investment to assess the financial needs of enterprises working in food value chains in Kenya and Tanzania. Their estimates showed that the total financing needs for investments to improve the delivery of nutritious foods from local companies in these two countries alone could be around US\$ 5.7 billion (26). One of the issues holding back this financing is that local banks often do not have the risk appetite to lend to the agri-food SME sector, about which they have little knowledge and which is relatively young and dynamic. Blended finance and impact investing, explained in the next section, are relatively recent innovations that can help overcome these barriers. For an example of potential benefits of providing funding and technical assistance to SMEs, see Box 1.

\subsection{BLENDED FINANCE AND IMPACT INVESTING}

Blended finance, or the use of public or philanthropic capital to spur private-sector investment in projects aimed at achieving sustainable development (27), offers a significant opportunity to make diets more sustainable, diverse, and nutritious. Blended finance can help de-risk and unlock the unmet investment needs among agri-food businesses, especially SMEs. The use of less risk-averse financing from the public sector can encourage more nutrition-sensitive private investment to flow into private-sector food businesses. 
In 2017, there were at least 300 closed blended finance transactions with an aggregate deal ${ }^{1}$ size of over US\$100 billion, doubling in size since 2012 (27). To date, relatively small amounts of blended finance have been dedicated to the agri-food sector, a little less than $5 \%$ (29). However, these investments are increasing year by year (29). Similarly, impact investing private investments made with the intention to generate a measurable, beneficial social or environmental impact alongside a financial return (30) -- has grown to 8,000 deals representing US\$ 114 billion in total assets (30). Impact investing in the agri-food sector is set to significantly increase in 2019 , although to date it has only represented $6 \%$ of total impact investments (30).

BOX 1. CASE STUDY: MARKETPLACE FOR NUTRITIOUS FOODS

The Marketplace for Nutritious Foods is a platform that focuses on providing funding and technical assistance to qualifying SMEs. In turn, this helps stimulate innovation, spurs growth, and helps businesses produce safe and nutritious foods for low-income consumers.

The Global Alliance for Improved Nutrition (GAIN), with support from USAID's Feed the Future Initiative, designed the programme in 2013. With technical and financial assistance, SMEs in, for example, horticulture and aquaculture value chains make their products more available, affordable, desirable, and/or profitable. The platform to date has worked with around 500 such firms to get more servings of nutritious foods (such as beans, fish, peanuts, and chicken) into markets in four countries in Africa, and to make those servings cheaper. Independent evaluations show some achievements. For example, one firm in Kenya has helped make tilapia fish affordable for $68 \%$ of the population (up from 49\%) in the region where it is operating (28). Over a period of four years, the grantees of the Marketplace for Nutritious Foods have produced over 34 million servings of low-cost, nutritious foods. Moving forward there is opportunity for this platform to incentivise the production of traditional crops, tree products, livestock. and fish to enhance agrobiodiversity.

\section{HOW CAN BLENDED FINANCE AND IMPACT INVESTING BE USED TO MAINSTREAM AGROBIODIVERSITY INTO SUSTAINABLE AND NUTRITIOUS FOOD SYSTEMS?}

The growing blended finance and impact investment space may represent a significant opportunity to leverage public and private financing and incentivise agri-food businesses to produce more agrobiodiversity.

A 2018 survey by the Global Impact Investing Network found that approximately half of impact investors anticipate growing their allocations to food and agriculture in 2019. Blended finance transactions into food and agriculture are also increasing rapidly. Energy and climate already represent one of the largest sectors that attracts blended finance and impact investment (e.g., $24 \%$ of all blended finance transactions are in renewable energy). There is

\footnotetext{
${ }^{1}$ An investment deal can be defined as an agreement to invest money in a given company, as detailed in a contract stating the rights and responsibilities of the two parties to the investment.
} 
thus a case to be made to impact investors and blended finance practitioners that multifunctional agro-ecological farming systems - especially if they can provide the diversity needed to cope with changing climates and extreme weather events - represent a win-win scenario for improving planetary and human health. This can be done by developing a compelling investment thesis and impact metrics that help blended finance practitioners and impact investors understand the intended social and financial impact of their investments into agrobiodiversity.

\section{PRIVATE SECTOR-LED INITIATIVES AND POLICIES}

Today, approximately 100 companies control $25 \%$ of the trade of the most significant food commodities on the planet; these commodities, in turn, are used in $40 \%-50 \%$ of all food production (31). Some of these companies are moving towards greater support for agrobiodiversity in their strategies. For example, one of the largest agricultural commodity traders globally, Cargill, consulted stakeholders in 2017 to formulate its new social and sustainability strategy. Cargill's 2018 Annual Report reported that it revised its agriculture practices to be more sustainable and highlighted ways it invested in biodiversity (32). There are also a variety of partnerships among these large, influential companies that are dedicated to improving sustainable and nutritious food systems. For example, the Sustainable Food Policy Alliance is a newly launched collaboration among four of the world's largest food manufacturers aiming to find solutions for sustainable agriculture systems that innovatively addresses climate change while better informing consumers about their food choices (33). These examples appear to provide some evidence of progress. However, independent assessments will need to be made on the abovementioned initiatives to see if these are translating into real actions that are improving the sustainability and nutrition of food systems - and such individual efforts will need to be scaled up to many more companies, and at a much larger scale to have a significant impact at the global level.

\section{WHAT IS THE ROLE OF AGROBIODIVERSITY IN PRIVATE-SECTOR LED INITIATIVES AND POLICIES?}

Significant gains could be made by the private sector taking the initiative to improve food systems. We suggest that biodiversity should be increasingly recognised as a critical business issue. There appears to be a positive shift occurring among the private sector away from pure profit-driven motives; greater support for agrobiodiversity is one of the potential directions the shift could take. An extensive global survey of CEOs revealed that $87 \%$ believe that the UN Sustainable Development Goals provide an opportunity to rethink approaches for sustainable value (34). This suggests that biodiversity and ecosystem considerations could become a more integral part of businesses' sustainability strategies.

The Agrobiodiversity Index, developed by Bioversity International with partners, could help provide guidance to large corporations (1). It can also drive forward accountability for privatesector commitments to agrobiodiversity and help recognise companies that are already improving their policies and actions related to agrobiodiversity. The Index is already being used to help some large food and agriculture companies make strategic supply chain decisions that can improve agrobiodiversity (1). 


\section{CONCLUSION}

Additional research is required to compile a comprehensive list of policies and actions which are moving food systems towards sustainability and enhanced agrobiodiversity, and to explore where there are trade-offs and synergies between agrobiodiversity and nutrition. However, this paper has highlighted a number of effective public policies, innovative financing mechanisms, and private sector-led initiatives that are already improving supply, nudging consumer food choices, and facilitating more appropriate private-sector engagement in food systems. It has explored ways that fiscal policies and subsidies could be used to support the increased production of biodiverse foods for a healthy, diverse diet. It has looked at existing public policies that improve micronutrient intake and how the lessons learned from successful implementation of these could be adapted to design policies that improve agrobiodiversity. The paper has also explored how momentum in the blended finance and impact investing fields could be leveraged to help drive new investments into agrobiodiversity. Lastly, the paper looked at the potential role of agrobiodiversity in privatesector led initiatives and policies.

Through targeted efforts there appears considerable scope to adapt policies, financing, and private sector-led initiatives to improve agrobiodiversity, which in turn can contribute to better nutrition, planetary health, and more productive food systems. 


\section{REFERENCES}

1. Bioversity International. Agrobiodiversity Index Report 2019: Risk and Resilience. 2019; Rome, Italy: Bioversity International. https://hdl.handle.net/10568/100820

2. China R: Mainstreaming Biodiversity into Sustainable Food Systems - We Need to Measure It. IISD SDG Knowledge Hub 2018; http://sdg.iisd.org/commentary/guestarticles/mainstreaming-biodiversity-into-sustainable-food-systems-we-need-tomeasure-it/ [Accessed January 14, 2019].

3. Powell $B$, et al. Improving diets with wild and cultivated biodiversity from across the landscape. Food Security 2015 7(3):535-554.

4. Berti PR: Relationship between production diversity and dietary diversity depends on how number of foods is counted. Proceedings of the National Academy of Sciences 2015; 112(42): E5656 https://doi.org/10.1073/pnas.1517006112.

5. Sibhatu, KT, Qaim, M. Farm production diversity and dietary quality: linkages and measurement issues. Food Security 2018;10(1): 47-59.

6. Frison EA, Smith IF, Johns T, Cherfas J, Eyzaguirre PB. Agricultural Biodiversity, Nutrition, and Health: Making a Difference to Hunger and Nutrition in the Developing World. Food and Nutrition Bulletin 2006;27(2):167-179.

7. Willett $W$, et al. Food in the Anthropocene: the EAT-Lancet Commission on healthy diets from sustainable food systems. The Lancet 2017; 393(10170):447-492.

8. Popkin BM, Reardon T: Obesity and the food system transformation in Latin America. Obesity Reviews. 2018; doi:10.1111/obr.12694.

9. Thiele S, Roosen J. Obesity, fat taxes and their effects on consumers. Regulating and Managing Food Safety in the EU: A Legal Perspective, eds Bremmers H, Purnhagen K (Springer International Publishing), 2018; pp 177-178.

10. WHO (World Health Organisation). Global Nutrition Policy Review 2016-2017. 2018. https://www.who.int/nutrition/topics/global-nutrition-policy-review-2016.pdf.

11. Niebylski ML, Redburn KA, Duhaney T, Campbell NR, Healthy food subsidies and unhealthy food taxation: A systematic review of the evidence. Nutrition. 2015; doi:10.1016/j.nut.2014.12.010.

12. FAO, IFAD, UNICEF, WFP, WHO. The State of Food Security and Nutrition in the World 2019. Safeguarding against economic slowdowns and downturns. Rome 2019, FAO.

13. Bailey R, Harper DR: Reviewing Interventions for healthy and sustainable diets Research Paper 2015; https://www.chathamhouse.org/sites/default/files/field/field_document/20150529Hea IthySustainableDietsBaileyHarperFinal.pdf [Accessed January 14, 2019].

14. World Cancer Research Fund International: NOURISHING framework - Use economic tools to address food affordability and purchase incentives. 2018;doi:10.1016/j.ypmed.2017.07.013.

15. Gradl C: Building a strategic alliance for the fortification of oil and other staple foods (SAFO) (World Cancer Research Fund, Cambridge, MA, USA) 2012; https://www.wcrf.org/sites/default/files/building-momentum.pdf.

16. Global Fortification Data Exchange(GFDx): Providing actionable food fortification data all in one place. https://fortificationdata.org/ [Accessed January 15, 2019]. 
17. Osendarp SJM, et al., Large-scale food fortification and biofortification in low- and middle-income countries: a review of programs, trends, challenges, and evidence gaps. Food and Nutrition Bulletin 2018; 39(2):315-331.

18. Bouis HE, Saltzman A, Improving nutrition through biofortification: A review of evidence from HarvestPlus, 2003 through 2016. Global Food Security 2017:12:49-58.

19. Baldermann, $S$ et al., Are Neglected Plants the Food for the Future?, Critical Reviews in Plant Sciences 2016, 35:2, 106-119, DOI: 10.1080/07352689.2016.1201399

20. Uarrota, V. G., et al., From Neglected and Underutilized Crops to Powerful Sources of Vitamin A: Three Case Studies of Mozambican Cultivated Tacca leontopetaloides, Cowpea, and Cassava. In Vitamin A. 2019 (ed) L. Q. Zepka, E. Jacob-Lopes and V. V. d. Rosso, Intechopen: Ch. 5.

21. IFPRI (International Food Policy Research Institute)2016 Global Nutrition Report From Promise to Impact: Ending Malnutrition by 2030 (IFPRI, Washington, DC).

22. Alpha Beta: Valuing the SDG prise in food and agriculture: Unlocking business opportunities to accelerate sustainable and inclusive growth 2016; http://s3.amazonaws.com/aws-bsdc/Valuing-SDG-Food-Ag-Prise-Paper.pdf [Accessed January 15, 2019].

23. Hatch G, Becker P, van Zyl M. The dynamic African consumer market: Exploring growth opportunities in sub-Saharan Africa (Accenture) 2011

24. UN Department of Economic and Social Affairs Population Division, Population Facts 2015;

http://www.un.org/en/development/desa/population/publications/pdf/popfacts/PopF acts_2015-1.pdf [Accessed January 15, 2019].

25. Reardon T. The hidden middle: the quiet revolution in the midstream of agrifood value chains in developing countries, Oxford Review of Economic Policy 2015; 31(1): 45-63. https://doi.org/10.1093/oxrep/grv011

26. GAIN (Global Alliance for Improved Nutrition), Investing in SMEs to improve the consumption of nutritious foods in Africa - Development Finance 2018;

https://www.devfinance.net/industry/investing-smes-improve-consumption-nutritiousfoods-africa/ [Accessed January 15, 2019].

27. Convergence, The State of Blended Finance 2018; https://downloads.ctfassets.net/4cgqlwde6qy0/6KN2rOUXAsceawYYywic86/154577e 7f96ed6511ef1048bc79ee978/State_of_Blended_Finance_2018_FINAL.pdf [Accessed January 15, 2019].

28. Haddad L: Reward food companies for improving nutrition. Nature 2018; 556(7699):19-22.

29. World Economic Forum and OECD, Insights from Blended Finance Investment Vehicles and Facilities 2016; http://www3.weforum.org/docs/WEF_Blended_Finance_Insights_Investments_Vehicle s_Facilities_report_2016.pdf [Accessed January 15, 2019].

30. Mudaliar A, Bass R, Associate S, Dithrich H: Annual Impact Investor Survey 2018 https://thegiin.org/assets/2018_GIIN_Annual_Impact_Investor_Survey_webfile.pdf [Accessed January 15, 2019]. 
31. WWF Transforming Business, Initiatives WWF

https://www.worldwildlife.org/initiatives/transforming-business [Accessed January 15, 2019].

32. Cargill Annual Report 2018; https://www.cargill.com/doc/1432124831909/2018annual-report.pdf [Accessed January 15, 2019].

33. Sustainable Brands. https://sustainablebrands.com/ [Accessed January 15, 2019].

34. World Cancer Research Fund International: Building momentum: Lessons on implementing a robust sugar sweetened tax 2018; www.wcrf.org/buildingmomentum [Accessed January 14, 2019]. 